\title{
LATIHAN AKURASI SHOOTING SEPAKBOLA: SASARAN GAWANG BESAR-KECIL DAN SASARAN BAN, MANA YANG EFEKTIF?
}

\section{FOOTBALL SHOOTING ACCURACY TRAINING: BIG-SMALL GOAL TARGET AND TIRE TARGET, WHICH ARE EFFECTIVE?}

\author{
Khoiril Anam ${ }^{1}$, Gading Maulana Zullfa², Fajar Awang Irawan ${ }^{3}$, Dhias Fajar Widya \\ Permana $^{4}$, Limpad Nurrachmad ${ }^{5}$, Nugroho Susanto ${ }^{6}$
}

\author{
1,2,3,4,5Fakultas Ilmu Keolahragaan, Universitas Negeri Semarang, Jawa Tengah, Indonesia \\ ${ }^{6}$ Fakultas Ilmu Keolahragaan, Universitas Negeri Padang, Sumatra Barat, Indonesia
}

\section{*Corresponding Author: Khoiril Anam, khoiril.ikor@mail.unnes.ac.id}

Received: 2021-10-14; Revised: 2021-11-15, Accepted: 2021-11-16

\begin{abstract}
Abstrak
Penelitian ini bertujuan untuk mengetahui manakah latihan yang lebih efektif antara latihan dengan sasaran gawang besar-kecil dan latihan dengan sasaran ban terhadap tingkat akurasi shooting pada permainan sepakbola. Jenis penelitian ini adalah eksperimen dengan desain penelitian menggunakan desain pretest-posttest control group design. Sampel penelitian ini menggunakan total sampling yang berjumlah 21 sampel. Instrumen yang digunakan adalah instrumen tes akurasi shooting sepakbola dengan validitas 0,85 dan reliabilitas 0,86 . Uji t-test digunakan sebagai analisis data dalam penelitian ini, dengan taraf signifikan 5\%. Analisis data menunjukkan kelompok kontrol memiliki signifikansi $0,689(\mathrm{p}<5 \%)$ yang berarti tidak ada pengaruh yang signifikan terhadap kemampuan akurasi shooting. Kelompok latihan sasaran gawang besar-kecil memiliki signifikansi 0,047 $(\mathrm{p}<5 \%)$ yang artinya ada pengaruh yang signifikan terhadap kemampuan akurasi shooting. Kelompok latihan sasaran ban signifikansi $0,003(\mathrm{p}<5 \%)$ yang berarti ada pengaruh yang signifikan terhadap kemampuan akurasi shooting. Hasil penelitian menunjukkan rata-rata skor kelompok latihan sasaran gawang besar-kecil pretest sebesar 34,29 dan posttest sebesar 37,86 dengan $\mathrm{p}=0,047$. Rata-rata skor kelompok latihan sasaran ban pretest sebesar 33,57 dan posttest sebesar 42,14 dengan p=0,003. Kesimpulan dalam penelitian ini adalah latihan sasaran ban lebih efektif dari pada latihan sasaran gawang besar kecil dalam meningkatkan akurasi shooting.
\end{abstract}

Kata Kunci: latihan akurasi, shooting, sepakbola

\section{Abstract}

This study aims to find out which training is more effective between training with large-small goal target and training with tire targets on the level of shooting accuracy in football. This type of research is an experimental research design using a pretest-posttest control group design. The sample of this study used a total sampling of 21 samples. The instrument used is a soccer shooting accuracy test instrument with a validity of 0.85 and a validity of 0.86. The t-test was used as data analysis in this study, with a significant level of 5\%. Data analysis showed that the control group had a significance of 0.689 ( $p<5 \%)$ which means that there is no significant effect on shooting accuracy. The large-small goal target training group had a significance of $0.047(p<5 \%)$ which means that there was a significant effect on shooting accuracy. The tire target training group had a significance of $0.003(p<5 \%)$ which means that there was a significant effect on shooting accuracy. The results showed that the average score of the large-small goal target training group for the pretest was 34.29 and the posttest was 37.86 with $p=0.047$. The average score of the tire target training group for the pretest was 33.57 and the posttest was 42.14 with $p=0.003$. The conclusion in this study is that the tire target training is more effective than the large-small goal target training in increasing shooting accuracy.

Keywords: accuracy training, shooting, football

Copyright (C) The Author (s) 2021

ISSN 2654-4474 (Print), ISSN 2654-9069 (Online) 
How To Cite: Anam , K., Zullfa , G.M., Irawan, F.A, Permana, D. F. W., Nurrachmad, L, Susanto, N. (2021). Latihan akurasi shooting sepakbola: sasaran gawang besar-kecil dan sasaran ban, mana yang efektif?. Journal Of Sport Education (JOPE), 4 (1), 55-63. doi:http://dx.doi.org/10.31258/jope.4.1.55-63

\section{PENDAHULUAN}

Sepakbola adalah permainan yang dimainkan oleh dua tim, dengan setiap tim berjumlah sebelas orang, satu dari sebelas orang di tim harus menjadi penjaga gawang, tujuan permainan sepakbola ini adalah untuk mencetak gol ke tim lain dan mencegah gol ke tim sendiri (Anam et al., 2018) (Ridwan, 2020) (IFAB, 2017). Teknik dasar sepakbola terdiri dari teknik dasar tanpa bola dan teknik dengan teknik bola, teknik dasar ini diperlukan untuk dapat memainkan sepakbola (Anam et al., 2019)(Darwis et al., 2020)(Gusdernawati et al., 2021)(Karahan, 2020).

Teknik dasar sepakbola terdiri dari teknik dasar dengan bola dan teknik dasar tanpa bola. Teknik menendang (kicking) merupakan salah satu teknik dasar dalam sepakbola yang termasuk dalam teknik dasar dengan bola (Anam, 2013)(Nunome et al., 2018). Teknik menendang merupakan dasar permainan sepak bola yang harus dikuasai oleh pemain (Torreblanca-Martinez et al., 2020)(Rodríguez-Lorenzo et al., 2015)(Bacvarevic et al., 2012)(Kellis et al., 2004), karena tim sepak bola yang baik adalah jika semua pemain menguasai teknik menendang bola dengan benar (Scoulding et al., 2017)(Campo et al., 2009). Analisis piala dunia sepak bola 2010 mengungkapkan bahwa 80,69\% gol dicapai dengan tendangan (Njororai, 2013). Tujuan utama attacking atau menyerang adalah mencetak gol ke gawang laewan, semakin baik tingkat akurasi umpan dan tendangan tiap pemain, maka kemungkinan penguasaan permainan di lapangan oleh sebuah tim semakin tinggi, dan peluang kemenangan tentunya ikut tinggi (Ferraz et al., 2019).

Akurasi merupakan kemampuan mengarahkan sesuatu ke sasaran yang dituju, sasaran dapat berupa sebuah objek yang dikenai (Hunter, Jr, et al., 2018)(Hunter, Murphy, et al., 2018). Akurasi dan sebuah tendangan dalam sepakbola memiliki hubungan yang erat. Pemain sepakbola yang memiliki kontrol bola dan dribble yang bagus akan menjadi sia-sia dalam suatu pertandingan jika yang bersangkutan tidak memiliki akurasi tendangan untuk mengoper bola kepada teman, dan penyelesaian akhir pastinya juga memerlukan akurasi yang baik juga (Anam K., 2013)(Palucci Vieira et al., 2021).

Berkaitan dengan ini, tendangan untuk penyelesaian akhir sangat penting dan menentukan kemenangan sebuah tim. Shooting merupakan sebuah tendangan keras yang mengarah ke sasaran gawang. Shooting mudah dilakukan akan tetapi memerlukan akurasi yang tinggi supaya shooting yang dilakukan sulit di antisipasi oleh kiper, sehingga membuahkan sebuah gol. Shooting yang baik adalah yang menggunakan punggung kaki atau instep kicking (Sterzing \& Hennig, 2008)(Lees et al., 2010)(Shinkai et al., 2009). Kekuatan tungkai dan sudut pengambilan tendangan merupakan kunci dari kecepatan atau kerasnya sebuah shooting (Witt \& Hinrichs, 2012)(Brophy et al., 2007)(Maly et al., 2018)(Heriyanto L., 2016). Dengan demikian pengembangan latihan tendangan diperlukan untuk meningkatkan kemampuan individu bagi setiap pemain (E Manolopoulos et al., 2006)(Young \& Rath, 2011)(Evaggelos Manolopoulos et al., 2013)(Augustus et al., 2017).

Salah satu variasi latihan untuk meningkatkan akurasi shooting adalah dengan memodifikasi sasaran atau target. Memodifikasi target dilakukan untuk meningkatkan perhatian (attention) bagi pemain. Fungsi perhatian visual telah dilaporkan penting untuk kinerja olahraga dalam situasi tekanan tinggi (Brimmell et al., 2021). Latihan sasaran menggunakan ban bekas dapat mengoptimalkan latihan shooting ini, penggunaan ban bekas ditujukan untuk meningkatkan ketepatan dalam penempatan bola pada sisi gawang (akurasi) 
dalam kemampuan shooting sepakbola (Abid W. M., dkk., 2015).

Metode latihan sasaran gawang besar-kecil merupakan salah satu variasi latihan akurasi tendangan dengan menempatkan dua gawang berukuran berbeda dengan jarak tertentu, dimana gawang utama (besar) atau gawang ukuran normal sebagai sasaran utama dan gawang kedua (kecil) sebagai penghalang atau bisa disebut pagar betis dalam sepakbola. Jarak antara gawang besar (utama) dan gawang kecil (penghalang) bisa diatur sebagaimana jarang tendangan bebas ideal dan jarak titik penendang dengan gawang kecil (pengalang) sesuai dengan jarak tembok pemain yaitu 9,15 meter (10 yard).

Metode latihan sasaran ban merupakan salah satu variasi latihan menendang bola dengan target, yang dimaksud di sini ban bekas dijadikan sebagai sasaran. Ban bekas digunakan untuk meningkatkan tingkat kesulitas pemain dalam mengarahkan bola. Hal ini dikarenakan salah satu faktor penentu ketepatan adalah tingkat kesulitan (Sukadiyanto, 2002). Pendapat lain juga menyatakan bahwa faktor internal yang mempengaruhi ketepatan yaitu koordinasi, ketajaman indera, penguasaan teknik, cepat lambatnya gerakan, ball feeling dan ketelitian, serta kuat atau lemahnya suatu gerakan. Sedangkan faktor eksternal yaitu besar kecilnya sasaran dan jauh dekatnya sasaran (Anam et al., 2018). Ban bekas digunakan sebagai titik sasaran pemain dalam latihan shooting untuk meningkatkan tingkat kesulitan pemain dalam latihan menendang. Selain itu, sasaran ban ini digunakan untuk menarik perhatian dan respon pemain agar lebih antusias dan bervariasi dalam latihan akurasi shooting.

Adapun kelebihan dari latihan sasaran gawang besar-kecil yaitu merupakan target asli, sudah ada di lapangan, kuat, dan awet, sedangkan sasaran ban memiliki kelebihan mudah di dapat, harganya murah, ringkas, mudah dibawa, dan ramah lingkungan. Kekurangan sasaran gawang besar-kecil yaitu susah di dapatkan, harganya mahal, berat, susah dipindahkan, sedangkan sasaran ban memiliki kekurangan tidak sesuai target asli, dan target susah dikenai.

Kedua metode latihan ini digunakan untuk meningkatkan akurasi shooting pemain Candika FC. Hal ini karena berdasarkan studi pendahuluan ditemukan adanya kesalahan yang dilakukan pemain Candika FC dalam finishing ke gawang, yaitu banyak yang diluar target. Berdasarkan data pertandingan di turnamen ditemukan bahwa pemain Candika FC melakukan 12 kali tendangan ke gawang dengan rincian 7 melenceng, 4 ditepis, dan 1 tercipta gol dengan persentase $8,3 \%$.

Tujuan penelitian ini untuk mengetahui yang lebih efektif antara latihan dengan sasaran gawang besar-kecil dan latihan dengan sasaran ban terhadap tingkat akurasi shooting pada permainan sepakbola.

\section{METODE}

Jenis penelitian yang digunakan adalah jenis penelitian eksperimen. Penelitian ini menggunakan desain pretest-posttest control group design. Sampel dibagi ke dalam tiga kelompok sesuai dengan ranking dari tes awal dengan cara zig-zag atau A-B-C-C-B-A, ini digunakan agar ketiga kelompok mempunyai kemampuan yang seimbang (equivalen). Kelompok pertama diberikan perlakuan latihan shooting sasaran gawang besar-kecil dan kelompok kedua diberi perlakuan dengan latihan shooting sasaran ban. Kelompok ketiga adalah kelompok pembanding/ kontrol di mana tidak ada perlakuan yang diberikan sama sekali.

Penelitian ini merupakan penelitian populasi dikarenakan populasi hanya berjumlah 21 pemain. Menurut (Arikunto, 2010) bila jumlah populasi kurang dari 30 orang, maka semua anggota populasi dijadikan sampel (total sampling). Instrumen dalam penelitian ini yaitu tes shooting ke gawang dengan tingkat validitas 0,85 dan reabilitas 0,86 (Wan Muhlish El Abid et al., 2013). Instrumen tes shooting ke gawang adalah tes menendang bola ke gawang dengan 
target gawang yang sudah dibagi menjadi 6 bidang, di mana tiap bidang memiliki skor tersendiri. Instrumen ini menggunakan ukuran gawang normal dengan 7,32 meter lebarnya dan 2,44 meter tingginya, kemudian gawang disusun menjadi 6 bidang dengan luas yang sama, setiap bidang memiliki nilai tersendiri. Jarak titik menendang dan gawang adalah 17 meter. Uji t-test digunakan sebagai analisis data dalam penelitian ini, dengan taraf signifikan $5 \%$ atau $\mathrm{P}>0,05$.

\section{HASIL}

Penelitian ini akan membahas mengenai data masing-masing pretest dan posttest dari tiga kelompok yaitu kelompok latihan dengan sasaran gawang besar-kecil, latihan dengan sasaran ban, dan kelompok kontrol. Data yang sudah di skor kemudian diolah dan diperoleh data dalam bentuk tabel sebagai berikut:

Tabel 1. Deskriptif data nilai skor akurasi shooting pretest dan posttest

\begin{tabular}{lccc}
\hline \multirow{2}{*}{ Kelompok } & N & \multicolumn{2}{c}{ Rata-rata \pm SD } \\
\cline { 3 - 4 } & 7 & Pre test & Post Test \\
\hline $\begin{array}{l}\text { Kontrol } \\
\text { Latihan sasaran }\end{array}$ & 7 & $33,57 \pm 8,997$ & $34,29 \pm 6,726$ \\
$\begin{array}{l}\text { gawang besar-kecil } \\
\text { Latihan sasaran }\end{array}$ & & $34,29 \pm 10,965$ & $37,86 \pm 11,495$ \\
ban & 7 & $33,57 \pm 8,997$ & $42,14 \pm 8,591$ \\
\hline
\end{tabular}

Sumber : Hasil Penelitian, 2021

Berdasarkan tabel 1 diketahui hasil tes rata-rata tes akurasi shooting pada kelompok latihan sasaran gawang besar-kecil dan latihan dengan sasaran ban mengalami peningkatan yang signifikan dibandingkan dengan kelompok kontrol.

Uji perbedaan rata-rata data pretest dan posttest dilakukan guna mengetahui ada tidaknya peningkatan sebelum dan sesudah diberikannya perlakuan (treatment). Selanjutnya data hasil pengukuran di analisis menggunakan paired sample t-test. Hasil perhitungan uji perbedaan rata-rata menghasilkan $t$ hitung dan signifikan sig.(2-tailed) yang digunakan untuk menguji hipotesis dan pengaruh. Jika $\mathrm{p}>5 \%$ maka Ho diterima, serta Ha ditolak. Jika $\mathrm{p}<5 \%$ maka Ho ditolak, serta Ha diterima. Perhitungan uji beda rata-rata paired sample t-test disajikan tabel berikut:

Tabel 2. Uji t-test pretest dan postest

\begin{tabular}{lllll}
\hline \multicolumn{1}{c}{ Kelompok } & \multirow{2}{*}{} & \multicolumn{2}{c}{ Rata-rata Skor Akurasi Shooting } & $\boldsymbol{p}$ \\
\cline { 3 - 5 } & & Pre test & Post test & 0,689 \\
Kontrol & 7 & 33,57 & 34,29 & 0,047 \\
Latihan Sasaran Gawang & 7 & 34,29 & 37,86 & 0,003 \\
Besar Kecil & 7 & 33,57 & 42,14 & \\
\hline
\end{tabular}

Sumber: Hasil Penelitian, 2021

Berdasarkan hasil penelitian rata-rata skor akurasi shooting kelompok kontrol pretest sebesar 33,57 dan posttest sebesar 34,29 dengan $\mathrm{p}=0,689(\mathrm{p}<5 \%)$ yang berarti tidak ada pengaruh yang signifikan pada kelompok kontrol terhadap kemampuan akurasi shooting pemain.

Berdasarkan hasil penelitian rata-rata skor akurasi shooting kelompok latihan sasaran gawang besar-kecil pretest sebesar 34,29 dan posttest sebesar 37,86 dengan $\mathrm{p}=0,047$, $(p<0,05)$ yang artinya ada pengaruh yang signifikan kelompok latihan sasaran gawang besar 
kecil terhadap kemampuan akurasi shooting pemain setelah diberikan perlakuan.

Berdasarkan hasil penelitian rata-rata skor akurasi shooting kelompok latihan sasaran ban pretest sebesar 33,57 dan posttest sebesar 42,14 dengan $\mathrm{p}=0,003(\mathrm{p}<5 \%)$ yang berarti ada pengaruh yang signifikan pada kelompok latihan sasaran ban terhadap kemampuan akurasi shooting setelah diberikan perlakuan (treatment).

Selisih rata-rata perbedaan pretest dan posttest dalam metode latihan menunjukkan sejauh mana metode yang lebih baik digunakan dalam meningkatakn akurasi shooting. Perbedaan rata-rata selisih antara hasil pretest dan posttest disajikan berikut.

Tabel 6. Selisih rata-rata antara Latihan Sasaran Gawang Besar Kecil dan Latihan sasaran Ban

\begin{tabular}{lllll}
\hline \multirow{2}{*}{ Kelompok } & N & \multicolumn{2}{l}{ Rata-rata Skor akurasi Shooting } & Selisih \\
\cline { 3 - 4 } & & Pretest & Posttest & \\
\hline $\begin{array}{l}\text { Latihan Sasaran Gawang Besar } \\
\text { Kecil }\end{array}$ & 7 & 34,29 & 37,86 & 3,57 \\
\hline Latihan Sasaran ban & 7 & 33,57 & 42,14 & 8,57 \\
\hline
\end{tabular}

Berdasarkan data di atas dapat diketahui bahwa selisih latihan sasaran ban lebih besar dibanding latihan sasaran gawang besar kecil dengan skor 8,57>3,57, dapat di simpulan bahwa latihan sasaran ban lebih efektif daripada latihan sasaran gawang besar kecil.

\section{PEMBAHASAN}

Berdasarkan hasil penelitian terdahulu, penelitian yang telah dilaksanakan ini memperkuat temuan penelitian sebelumnya. Hal bisa dilihat dengan ditemukannya bahwa latihan untuk meningkatkan akurasi tendangan dalam hal ini shooting, lebih efektif menggunakan sasaran ban, di mana metode ini sasaran ban yang digunakan adalah dalam posisi tetap dan tidak bergerak.

Latihan merupakan kegiatan yang memiliki tujuan meningkatakan suatu keterampilan olahraga dengan menggunakan peralatan yang sesuai tujuan latihan yang diinginkan (Anam, 2013). Berdasarkan penelitian yang telah dilakukan, ditemukan bahwa latihan menggunakan sasaran ban terbukti lebih efektif dari pada latihan menggunakan sasaran gawang besar kecil dalam hal meningkatkan akurasi shooting, dengan melihat dari data selisih rata-rata skor latihan menggunakan sasaran ban $(8,57)$ lebih besar dibanding latihan menggunakan sasaran gawang besar-kecil $(3,57)$.

Hal ini bisa terjadi karena dalam permainan sepakbola, shooting merupakan teknik menendang bola yang dilakukan dengan tujuan untuk mencetak gol ke gawang lawan. Oleh karena itu, teknik menendang bola ini harus dilatih terus menerus agar mendapatkan keterampilan yang maksimal. Dalam melatih akurasi shooting diperlukan koordinasi yang baik antara mata dan kaki (Anam et al., 2018). Koordinasi merupakan kemampuan seseorang dalam melakukan gerakan secara cepat dan tepat secara efesien (Irianto, 2002). Ketika seorang ingin melakukan gerakan dari yang sederhana sampai yang kompleks, semuanya diatur dan diperintah oleh system syaraf pusat yang sebelumnya sudah tersimpan di dalam memori. Oleh karena itu, sistem syaraf pusat sebagai pengendali gerakan beserta sistem syaraf tepi dengan otot dan sendi selalu terlibat dalam gerakan koordinasi, termasuk dalam gerakan koordinasi shooting.

Latihan koordinasi mata-kaki diperlukan untuk meningkatkan akurasi tendangan, oleh karena itu diperlukan latihan terus menerus menggunakan berbagai metode latihan (Anam et al., 2018). Hal ini juga telah disampaikan oleh penelitian Khoiril Anam dengan judul artikel "pengaruh metode latihan dan koordinasi mata-kaki terhadap ketepatan tendangan jarak 
jauh". Hasil penelitian tersebut menunjukkan bahwa pemain dengan koordinasi mata-kaki tinggi atau bagus, lebih cocok dilatih menggunakan metode latihan sasaran tetap. Selain itu, untuk pemain dengan koordinasi mata-kaki rendah lebih cocok dilatih menggunakan metode latihan sasaran tetap (Anam et al., 2018).

Metode latihan sasaran ban merupakan salah satu variasi latihan menendang bola dengan target, yang dimaksud di sini ban bekas dijadikan sebagai sasaran. Ban bekas digunakan untuk meningkatkan tingkat kesulitas pemain dalam mengarahkan bola. Hal ini dikarenakan salah satu faktor penentu ketepatan adalah tingkat kesulitan (Sukadiyanto, 2002). Pendapat lain juga menyatakan bahwa faktor internal yang mempengaruhi ketepatan yaitu koordinasi, ketajaman indera, penguasaan teknik, cepat lambatnya gerakan, ball feeling dan ketelitian, serta kuat atau lemahnya suatu gerakan. Sedangkan faktor eksternal yaitu besar kecilnya sasaran dan jauh dekatnya sasaran (Anam et al., 2018).Ban bekas digunakan sebagai titik sasaran pemain dalam latihan shooting untuk meningkatkan tingkat kesulitan pemain dalam latihan menendang. Selain itu, sasaran ban ini digunakan untuk menarik perhatian dan respon pemain agar lebih antusias dan bervariasi dalam latihan akurasi shooting. Adapun kelebihan dari latihan sasaran ban yaitu memiliki kelebihan mudah di dapat, harganya murah, ringkas, mudah dibawa, dan ramah lingkungan. Sedangkan kekurangan sasaran gawang besar-kecil sasaran ban memiliki kekurangan tidak sesuai target asli, dan target susah dikenai.

Penelitian ini dilakukan nantinya memiliki dampak terhadap perkembangan dalam kepelatihan sepakbola. Di mana temuan ini dapat digunakan sebagai referensi tambahan dalam melakukan latihan menendang bola yang akurat. Selain itu, hasil temuan ini juga dapat digunakan sebagai referensi tambahan bagi peneliti-peneliti dimasa mendatang. Keterbatasan dalam penelitian ini adalah masih sedikit dalam hal sampel penelitian dalam grup penelitian yang dibentuk, dan juga terkendala lapangan untuk latihan yang masih kurang standar.

\section{SIMPULAN}

Simpulan dalam penelitian ini adalah metode latihan ketepatan dengan sasaran ban lebih baik daripada metode latihan dengan sasaran gawang besar-kecil. Metode latihan sasaran ban membantu pemain untuk melatih memfokuskan tendangan untuk mengenai target yang dituju atau melatih fokus ke satu titik, dibanding metode latihan sasaran gawang besar-kecil yang memiliki target yang besar sehingga dapat memecah fokus. Metode ini direkomendasikan digunakan sebagai variasi latihan akurasi menendang dan dapat digunakan sebagai acuan dasar untuk penelitian selanjutnya yang relevan.

\section{DAFTAR PUSTAKA}

Abid, Wan Muhlish El, Purnomo, E., \& Kresnadi, H. (2013). Pengaruh Latihan Sasaran Menggunakan Ban Bekas Terhadap Hasil Shooting Permainan Sepakbola Siswa Hidayatul Muhsinin. Jurnal Pendidikan Dan Pembelajaran Khatulistiwa, 2(12).

Abid, Wan Mushlish, Purnomo, E., \& Kresnadi, H. (2015). Pengaruh latihan sasaran menggunakan ban bekas terhadap hasil. 1-10.

Anam, K. (2013). Pengembangan Latihan Ketepatan Tendangan Dalam Sepakbola Untuk Anak Kelompok Umur 13-14 Tahun. Jurnal Media Ilmu Keolahragaan Indonesia, 3(2), 78-88. https://doi.org/10.15294/miki.v3i2.4377

Anam, K., Irawan, F. A., \& Nurrachmad, L. (2018). Pengaruh Metode Latihan dan Koordinasi Mata-Kaki terhadap Ketepatan Tendangan Jarak Jauh. Media Ilmu Keolahragaan 
Journal Of Sport Education (JOPE), 4 (1) 2021 - 61

Khoiril Anam ${ }^{*}$, Gading Maulana Zullfa² , Fajar Awang Irawan ${ }^{3}$, Dhias Fajar Widya Permana ${ }^{4}$, Limpad Nurrachmad $^{5}$, Nugroho Susanto 6

Indonesia, 8(2), 57-62. https://doi.org/10.15294/miki.v8i2.17184

Anam, K., Subiyono, H. S., \& Rahman, M. A. (2019). Profile of Physical Conditions from UNNES Football Club at Liga Mahasiswa Piala MENPORA 2019. 5th International Conference on Physical Education, Sport, and Health (ACPES 2019), 77-81.

Arikunto, S. (2010). Prosedur Penelitian Suatu Pendekatan Praktik. Jakarta: Rineka Cipta.

Augustus, S., Mundy, P., \& Smith, N. (2017). Support leg action can contribute to maximal instep soccer kick performance: an intervention study. Journal of Sports Sciences, 35(1), 89-98. https://doi.org/10.1080/02640414.2016.1156728

Bacvarevic, B. B., Kukolj, M., Pazin, N., Jaric, S., Bozi, P. R., \& Mirkov, D. (2012). Evaluation of a composite test of kicking performance. Journal of Strength and Conditioning Research, 26(7), 1945-1952. https://doi.org/10.1519/JSC.0b013e318237e79d

Brimmell, J., Edwards, E. J., Smith, M., \& Vaughan, R. S. (2021). Think, see, do: Executive function, visual attention, and soccer penalty performance. Sport, Exercise, and Performance Psychology, 10(2), 290-309. https://doi.org/10.1037/SPY0000265

Brophy, R. H., Backus, S. I., Pansy, B. S., Lyman, S., \& Williams, R. J. (2007). Lower extremity muscle activation and alignment during the soccer instep and side-foot kicks. The Journal of Orthopaedic and Sports Physical Therapy, 37(5), 260-268. https://doi.org/10.2519/JOSPT.2007.2255

Campo, S. S., Ana, M., Trigueros, D. B., Carlos, J., \& Castán, R. (2009). Validación de un protocolo para la medición de la velocidad de golpeo en fútbol. Apunts: Educación Física y Deportes, 2(96), 42-46.

Darwis, Z., Melati, S., \& Riau, U. I. (2020). Vo2 max klub sepakbola garuda muda kecamatan kuok. Journal of Sport Education (JOPE), 2(2), 79-86.

Ferraz, R. M. P., Tillaar, R. van den, Pereira, A., \& Marques, M. C. (2019). The effect of fatigue and duration knowledge of exercise on kicking performance in soccer players. Journal of Sport and Health Science, 8(6), 567-573. https://doi.org/10.1016/J.JSHS.2016.02.001

Gusdernawati, A., Mahatmasari, P. Y., Suherman, W. S., Lituhayu, K., \& Umam, A. K. (2021). Analisis Kelincahan, Kecepatan, dan Koordinasi Mata-Kaki dengan Kemampuan Dribbling Tim Sepak Bola USS (Uir Soccer School). Journal of Sport Education (JOPE), 3(2), 63-74.

Heriyanto, L. (2016). Pengaruh Latihan Variasi Menendang Ke Berbagai Sasaran Untuk Meningkatkan Ketepatan Shooting Menggunakan Punggung Kaki Siswa Yang Mengikuti Ekstrakurikuler Di Smp N 2 Depok Tahun 2016. 1-10.

Hunter, A. H., Jr, M. J. A., Pavlic, T., Lichtwark, G., \& Wilson, R. S. (2018). Modeling the twodimensional accuracy of soccer kicks. Journal of Biomechanics, 72, 159-166. https://doi.org/10.1016/J.JBIOMECH.2018.03.003

Hunter, A. H., Murphy, S. C., Michael J. Angilletta, J., \& Wilson, R. S. (2018). Anticipating the 
direction of soccer penalty shots depends on the speed and technique of the kick. Sports, 6(3). https://doi.org/10.3390/SPORTS6030073

IFAB. (2017). Laws of the game 2017/18. Zurich: IFAB.

Irianto, D. P. (2002). Pedoman Praktis Berolahraga untuk Kebugaran dan Kesehatan. Yogyakarta : Andi Offset.

Karahan, M. (2020). Effect of skill-based training vs. small-sided games on physical performance improvement in young soccer players. Biology of Sport, 37(3), 305-312. https://doi.org/10.5114/biolsport.2020.96319

Kellis, E., Katis, A., \& Gissis, I. (2004). Knee biomechanics of the support leg in soccer kicks from three angles of approach. Medicine and Science in Sports and Exercise, 36(6), 10171028. https://doi.org/10.1249/01.MSS.0000128147.01979.31

Lees, A., Asai, T., Andersen, T. B., Nunome, H., \& Sterzing, T. (2010). The biomechanics of kicking in soccer: a review. Journal of Sports Sciences, 28(8), 805-817. https://doi.org/10.1080/02640414.2010.481305

Maly, T., Sugimoto, D., Izovska, J., Zahalka, F., \& Mala, L. (2018). Effect of Muscular Strength, Asymmetries and Fatigue on Kicking Performance in Soccer Players. International Journal of Sports Medicine, 39(4), 297-303. https://doi.org/10.1055/S-0043-123648

Manolopoulos, E, Papadopoulos, C., \& Kellis, E. (2006). Effects of combined strength and kick coordination training on soccer kick biomechanics in amateur players. Scandinavian Journal of Medicine \& Science in Sports, 16(2), 102-110. https://doi.org/10.1111/J.16000838.2005.00447.X

Manolopoulos, Evaggelos, Katis, A., Manolopoulos, K., Kalapotharakos, V., \& Kellis, E. (2013). Effects of a 10-week resistance exercise program on soccer kick biomechanics and muscle strength. Journal of Strength and Conditioning Research, 27(12), 3391-3401. https://doi.org/10.1519/JSC.0B013E3182915F21

Njororai, W. W. S. (2013). Analysis of goals scored in the 2010 world cup soccer tournament held in South Africa. Journal of Physical Education and Sport, 13(1), 6-13. https://doi.org/10.7752/jpes.2013.01002

Nunome, H., Inoue, K., Watanabe, K., Iga, T., \& Akima, H. (2018). Dynamics of submaximal effort soccer instep kicking. Journal of Sports Sciences, 36(22), 2588-2595. https://doi.org/10.1080/02640414.2018.1470216

Palucci Vieira, L. H., Santinelli, F. B., Carling, C., Kellis, E., Santiago, P. R. P., \& Barbieri, F. A. (2021). Acute Effects of Warm-Up, Exercise and Recovery-Related Strategies on Assessments of Soccer Kicking Performance: A Critical and Systematic Review. Sports Medicine, 51(4), 661-705. https://doi.org/10.1007/S40279-020-01391-9

Ridwan, M. (2020). Small sided games meningkatkan kebugaran jasmani dan keterampilan bermain sepakbola. Journal of Sport Education (JOPE), 3(1), 35. 
https://doi.org/10.31258/jope.3.1.35-42

Rodríguez-Lorenzo, L., Fernandez-Del-Olmo, M., \& Martín-Acero, R. (2015). A critical review of the technique parameters and sample features of maximal kicking velocity in soccer. $\begin{array}{llll}\text { Strength and } \quad \text { Conditioning 26-39. } & \text { Journal, }\end{array}$ https://doi.org/10.1519/SSC.0000000000000172

Scoulding, A., James, N., \& Taylor, J. (2017). Passing in the Soccer World Cup 2002. Http://Dx.Doi.Org/10.1080/24748668.2004.11868302, 36-41. https://doi.org/10.1080/24748668.2004.11868302

Shinkai, H., Nunome, H., Isokawa, M., \& Ikegami, Y. (2009). Ball impact dynamics of instep soccer kicking. Medicine and Science in Sports and Exercise, 41(4), 889-897. https://doi.org/10.1249/MSS.0B013E31818E8044

Sterzing, T., \& Hennig, E. M. (2008). The influence of soccer shoes on shooting velocity during full instep kicking. 36(2), 91-97.

Sukadiyanto. (2002). Pembinaan kondisi fisik petenis. Yogyakarta: Universitas Negeri Yogyakarta.

Torreblanca-Martinez, V., Nevado-Garrosa, F., Otero-Saborido, F. M., \& Gonzalez-Jurado, J. A. (2020). Effects of fatigue induced by repeated-sprint on kicking accuracy and velocity in female soccer players. PLoS ONE, 15(1), 1-12. https://doi.org/10.1371/journal.pone.0227214

Witt, J. K. De, \& Hinrichs, R. N. (2012). Mechanical factors associated with the development of high ball velocity during an instep soccer kick. Sports Biomechanics, 11(3), 382-390. https://doi.org/10.1080/14763141.2012.661757

Young, W. B., \& Rath, D. A. (2011). Enhancing foot velocity in football kicking: the role of strength training. Journal of Strength and Conditioning Research, 25(2), 561-566. https://doi.org/10.1519/JSC.0B013E3181BF42EB 